OPEN ACCESS

Edited by:

Yanzhu Zhu,

Chinese Academy of Agricultural Sciences (CAAS), China

Reviewed by:

Jianguo Wang,

Northwest A\&F University, China

Albert $P$ Li,

In Vitro ADMET Laboratories, United States

*Correspondence:

Zeyad Alehaideb

alehaidebze1@ngha.med.sa

Specialty section:

This article was submitted to

Predictive Toxicology,

a section of the journal

Frontiers in Pharmacology

Received: 13 December 2020

Accepted: 02 March 2021

Published: 29 April 2021

Citation:

Alehaideb Z, Sheriffdeen M and Law FCP (2021) Inhibition of Caffeine

Metabolism by Apiaceous and Rutaceae Families of Plant Products in Humans: In Vivo and In Vitro Studies.

Front. Pharmacol. 12:641090.

doi: $10.3389 /$ fphar.2021.641090

\section{Inhibition of Caffeine Metabolism by Apiaceous and Rutaceae Families of Plant Products in Humans: In Vivo and In Vitro Studies}

\author{
Zeyad Alehaideb ${ }^{1,2,3 *}$, Mohamed Sheriffdeen ${ }^{4}$ and Francis C. P. Law ${ }^{5}$ \\ ${ }^{1}$ Department of Medical Research Core Facility and Platforms, King Abdullah International Medical Research Center, Riyadh, \\ Saudi Arabia, ${ }^{2}$ King Saud Bin Abdulaziz University for Health Sciences, Riyadh, Saudi Arabia, ${ }^{3}$ Ministry of National Guard - Health \\ Affairs, Riyadh, Saudi Arabia, ${ }^{4}$ Life Sciences Division, SGS Canada Inc., Mississauga, ON, Canada, ${ }^{5}$ Department of Biological \\ Sciences, Faculty of Science, Simon Fraser University, Burnaby, BC, Canada
}

Daily consumption of caffeinated beverages is considered safe but serious health consequences do happen in some individuals. The Apiaceous and Rutaceae families of plant (ARFP) products are popular foods and medicines in the world. We previously reported significant amounts of furanocoumarin bioactive such as 8-methoxypsoralen, 5methoxypsoralen, and isopimpinellin in ARFP products. As both caffeine and furanocoumarin bioactive are metabolized by the same hepatic CYP1A1/2 isozyme in humans, caffeine/ARFP product interactions may occur after co-administration. The objectives of the present study were to study in vivo loss of caffeine metabolizing activity by comparing the pharmacokinetics of caffeine in volunteers before and after pre-treatment with an ARFP extract, study the correlation between the decrease in hepatic CYP1A2 activity and the content of furanocoumarin bioactive in ARFP extracts, characterize CYP1A2 inactivation using in vitro incubations containing ${ }^{14} \mathrm{C}$-caffeine, a furanocoumarin bioactive, and human liver microsomes (HLMs), and provide a mechanistic explanation for both in vivo and in vitro data using the irreversible inhibition mechanism. The study results showed pre-treatment of volunteers with four ARFP extracts increased the area-under-the-concentration-time-curve $\left(\mathrm{AUC}_{0 \text {-inf }}\right)$ ratio of caffeine in the plasma ranging from 1.3 to 4.3 -fold compared to the untreated volunteers indicating significant caffeine metabolism inhibition. The increases in $\mathrm{AUC}_{0 \text {-inf }}$ ratio also were linearly related to the effect-based doses of the furanocoumarins in the ARFP extracts, a finding which indicated caffeine metabolism inhibition was related to the content of furanocoumarin bioactive in an ARFP product. In vitro incubation studies also showed individual furanocoumarin bioactive were potent inhibitors of caffeine-N-demethylation; the

\footnotetext{
Abbreviations: 5-MOP, 5-methoxypsoralen; 8-MOP, 8-methoxypsoralen; ISOP, isopimpinellin; ARF, Apiaceae and Rutaceae families; AUC, area-under-the-concentration-time-curve; AUC0-inf, AUC from time zero time to infinity; CL, oral clearance; Cmax, maximum concentration; CO, carbon monoxide; CYP, cytochrome 450P; DMSO, dimethyl sulfoxide; HLMs, human liver microsomes; HPLC-UV, high-performance liquid chromatography and ultra-violet detector; $\mathrm{IC}_{50}$, inhibition concentration at 50\%; ISTD, internal standard; KI, irreversible inhibition constant; kinact, maximum inactivation rate constant; kobs, observed rate constant; Ln, natural logarithm; NADPH, $\beta$-nicotinamide adenine dinucleotide phosphate hydrogen; $\mathrm{N}_{2}$, nitrogen gas; $\mathrm{O}_{2}$, oxygen gas; PUVA, psoralen and ultra-violet A; SPE, solid-phase extraction; SD, standard deviation; TCA, trichloroacetic acid; Tmax, time at maximum concentration.
} 
$\mathrm{IC}_{50}$ for 8-methoxypsoralen 5-methoxypsoralen, and isopimpinellin were 0.09, 0.13, and $0.29 \mu \mathrm{M}$, respectively. In addition, CYP1A2 inactivation by individual furanocoumarin bioactive was concentration- and time-dependent involving the irreversible inhibition mechanism. The proposed irreversible inhibition mechanism was investigated further using ${ }^{14} \mathrm{C}$-labeled 8-methoxypsoralen and HLMs. The formation of ${ }^{14} \mathrm{C}$-adducts due to ${ }^{14} \mathrm{C}-8-\mathrm{MOP}$-derived radioactivity bound to HLMs confirmed the irreversible inhibition of CYP1A2 activity. Thus, furanocoumarin bioactive metabolism in humans would result in reactive metabolite(s) formation inactivating CYP1A2 isozyme and inhibiting caffeine metabolism. Once the CYP1A2 isozyme was deactivated, the enzymic activity could only be regained by isozyme re-synthesis which took a long time. As a result, a single oral dose of ARFP extract administered to the human volunteers $3.0 \mathrm{~h}$ before still was able to inhibit caffeine metabolism.

Keywords: caffeine, furanocoumarin, enzyme inactivation mechanism, P450 cytochrome enzymes, chemical mixtures

\section{HIGHLIGHTS:}

- A single oral dose of an ARFP extract administered to humans $3 \mathrm{~h}$ before is still able to inhibit caffeine metabolizing activity.

- The degree of caffeine metabolism inhibition is linearly related to an increasing effect-based dose of the furanocoumarin mixture in the ARFP extracts.

- Individual furanocoumarin chemicals inactivate CYP 1A2 enzyme in a time- and concentration-dependent manner which indicates involvement of the irreversible inhibition mechanism.

- The long inhibitory effects of ARFP on caffeine metabolism are explainable by CYP $1 \mathrm{~A} 2$ inactivation.

\section{INTRODUCTION}

Caffeine (Figure 1) is a popular human stimulant. About $100 \mathrm{mg}$ of caffeine is consumed by each person daily in the form of coffee, tea and/or cocoa (FAOSTAT, 2009). The caffeine consumption level would be higher if energy drinks, fitness supplements, and caffeine-containing drugs were included in the estimation (Goldstein et al., 2010; Lipton et al., 2017). Caffeine is often used to improve physical and/or cognitive performance in humans (Glade, 2010). Using caffeine in moderation is safe, but excessive usage would lead to serious health problems such as severe cardiac arrhythmia, delirium, seizures (Nawrot et al., 2003; Akter et al., 2016; Wikoff et al., 2017), and even death (Jabbar and Hanly, 2013).

The pharmacokinetics of caffeine in humans has been studied in great details (Tang-Liu et al., 1983). Caffeine is almost completely absorbed by humans after oral administration and caffeine usually reaches the peak concentration in the blood within $1.0 \mathrm{~h}$ after receiving a single oral dose. Caffeine is metabolized by the hepatic cytochrome (CYP) 1A2 isozyme of humans mainly to paraxanthine (Kot and Daniel, 2008) with less than 3\% of the administered dose eliminated as unchanged drug (Tang-Liu et al., 1983). The half-life of caffeine in the plasma is reported to range from 2.7 to $9.9 \mathrm{~h}$ (Blanchard and Sawers, 1983). Thus, the pharmacokinetics of caffeine in the plasma of humans shows significant inter- and intra-individual differences (Tian et al., 2019).

Previous studies have shown that the furanocoumarin bioactive in grapefruits (Guo and Yamazoe, 2004) and herbaceous plants (Zhuang et al., 2013) are potent CYP enzyme inhibitors. However, little is known of the inhibitory effects of the Apiaceous and Rutaceae families of plant (ARFP) products on human CYP enzymes. The ARFP products are popular foods and traditional medicines in the Middle East and Asia. In an earlier study, we screened over 29 products from the ARFP for linear furanocoumarins using high-performance liquid chromatography equipped with an ultra-violet detector (HPLCUV), and gas chromatography with mass spectrometry (Alehaideb et al., 2017). Our results showed significant levels of 8methoxypsoralen (8-MOP), 5-methoxypsoralen (5-MOP), and isopimpinellin (ISOP) (Figure 1) were found in 9 of the ARFP products; total linear furanocoumarins in these ARFP products ranged from 0.016 to $11.468 \mathrm{mg} / \mathrm{g}$ dry weight. It should be noted that linear furanocoumarins are chemical derivatives of psoralen whereas angular furanocoumarins are derivatives of isopsoralen which is an isomer of psoralen (Berenbaum, 1983). Also, linear furanocoumarins such as psoralen (Zhuang et al., 2013), ISOP (Kang et al., 2011), imperatorin and isoimperatorin (Cao et al., 2013), and bergamottin (Lim et al., 2005) have been identified as inhibitors of human CYP 1A2 enzyme.

The objectives of the present study were: to investigate nine selected ARFP products for the potential to inhibit caffeine metabolism by comparing the pharmacokinetics of caffeine in humans before and after pre-treatment with an ARFP extract, to determine the relationship between the area-under-theconcentration-time-curve (AUC) ratio of caffeine and the content of furanocoumarin bioactive in an ARFP extract, to study in vitro CYP $1 \mathrm{~A} 2$ inactivation with incubations containing ${ }^{14} \mathrm{C}$-caffeine, a furanocoumarin inhibitor, and human liver microsomes (HLMs), and to propose an inhibition mechanism to explain the in vivo and in vitro data. 
<smiles>Cn1c(=O)c2c(ncn2C)n(C)c1=O</smiles>

Caffeine<smiles>COc1c2occc2cc2ccc(=O)oc12</smiles>

8-methoxypsoralen (8-MOP)<smiles>COc1c2ccoc2cc2oc(=O)ccc12</smiles>

5-methoxypaoralen (5-MOP)<smiles>COc1c2ccoc2c(OC)c2oc(=O)ccc12</smiles>

Isopimpinellin (ISOP)
FIGURE 1 | Chemical structures of caffeine and linear furanocoumarins.

It is important to study CYP $1 \mathrm{~A} 2$ inactivation by ARFP products in humans. Although the CYP 1A2 isozyme accounts for just $13 \%$ of the total hepatic CYP pool (Shimada et al., 1994), it plays an important role in the biotransformation of prescription drugs and pro-carcinogens. As such inactivation of CYP $1 \mathrm{~A} 2$ by ARFP products has both beneficial and harmful health effects: the beneficial effects include the prevention of carcinogenesis by decreasing pro-carcinogen activation whereas the harmful effects include caffeine overdose as a result of caffeine/ARFP product interaction.

\section{MATERIALS AND METHODS}

\section{Source of Plant Products, Chemicals, and Human Liver Microsomes Apiaceae and Rutaceae Families of Plant Products}

We selected nine ARFP products for the present study based on the results of an earlier study (Alehaideb et al., 2017). The selected ARFP products were Ammi majus L. (A. majus) purchased from EverWilde (Fallbrook, CA), Angelica archangelica L. seeds (A. archangelica), A. graveolens seeds (A. graveolens S), Pimpinella anisum L. seeds (P. anisum), and Ruta graveolens L. leaves $(R$. graveolens) were purchased from Mountain Rose (Eugene, OR). Apium graveolens L. flakes (A. graveolens F) and Petroselinum crispum (Mill.) Fuss leaves ( $P$. crispum) were purchased from A1SpiceWorld (Glen Head, NY). Angelica pubescens Maxim. roots (A. pubescens) purchased from Spring Wind (San Francisco, CA), Cnidium monnieri (L.) Cusson (C. monnieri) were purchased from Health and Wellness House (Duncan, BC).
These nine ARFP products were authenticated by the suppliers and certified to be free of pesticides and preservatives. Further authentication was performed by measurement of furanocoumarin levels chromatographically in the aforementioned ARFP as seen in Table 1. The furanocoumarins in the aqueous extracts were separated using a gradient program consisting of acetonitrile and water and detected by UV set at $310 \mathrm{~nm}$ for $40 \mathrm{~min}$. The measured levels of linear furanocoumarins in ARFP were compared with previously published levels in same plant species (Alehaideb et al., 2017). Voucher samples were kept for future reference and certificates are available upon request.

\section{Chemicals}

Benzotriazole (99.0\%), caffeine ( $\geq 99.0 \%)$, ethyl acetate $(\geq 99.7 \%)$, 8-MOP ( $\geq 98.0 \%), 5$-MOP (99.0\%), and $\beta$-nicotinamide adenine dinucleotide phosphate reduced form (NADPH) $(\geq 97.0 \%)$, were obtained from Sigma-Aldrich (St. Louis, MO). Methanol $(\geq 99.9 \%)$ and acetonitrile $(\geq 99.9 \%)$ were obtained from Thermo Fisher Scientific (Hampton, NH) and Sigma-Aldrich. Acetic acid ( $\geq 99.7 \%)$, trichloroacetic acid (TCA) ( $\geq 99.0)$, dipotassium phosphate $\left(\mathrm{K}_{2} \mathrm{HPO}_{4}\right) \quad(\geq 60.0)$, and monopotassium phosphate $\left(\mathrm{KH}_{2} \mathrm{PO}_{4}\right)(\geq 60.0)$ were obtained from Anachemia (Rouses Point, NYC). ISOP was obtained from ChromaDex (Irvine, CA) (98.3\%) and Sigma-Aldrich $(\geq 95.0 \%)$. Spectral grade dimethyl sulfoxide (DMSO) was obtained from Caledon (Georgetown, ON). High-purity nitrogen gas $\left(\mathrm{N}_{2}\right)$, oxygen gas $\left(\mathrm{O}_{2}\right)$, and carbon monoxide (CO) gas was obtained from Praxair (Danbury, CT).

$\left[3^{\prime}-N-{ }^{14} \mathrm{C}\right.$-methyl]-Caffeine (specific activity $50-60 \mathrm{mCi} /$ mmol) was obtained from American Radiolabeled Chemicals (St. Louis, MO). The methyl- ${ }^{14} \mathrm{C}$ labeled 8 -MOP, specific activity of $40-60 \mathrm{mCi} / \mathrm{mmol}$, was purchased from Vitrax Radiochemicals (Placentia, CA). Scintillation cocktail fluids were obtained from Perkin Elmer Life Sciences (Waltham, MA) and Amersham Biosciences (Piscataway, NJ). Ultrapure water was produced using a Millipore system (Billerica, MA) with a minimum resistivity of $16.0 \mathrm{M} \Omega \mathrm{cm}$ at $25^{\circ} \mathrm{C}$.

\section{Human Liver Microsomes (HLMs)}

Pooled HLMs were purchased from BD Gentest (Franklin Lakes, NJ; catalog number 452161 and lot numbers of 99268 and 18888) and GIBCO (Waltham, Massachusetts, catalog number HMMCPL and lot number PL050B).

\section{Caffeine Pharmacokinetics in Humans Before and After ARFP Extract Pre-treatment \\ Volunteer Eligibility and Selection}

Male human volunteers, between 21 and 30 years old and living in the Metro Vancouver area, were recruited for the study. The volunteers had to meet specific eligibility criteria: not smoking, use medication, consume alcohol heavily or have any health concerns which may affect the test results. The volunteers were asked to avoid consuming caffeinated drinks and caffeine-containing foods for $12.0 \mathrm{~h}$ prior to and during the 
TABLE 1 | The amounts of linear furanocoumarins found in various ARFP products.

\begin{tabular}{|c|c|c|c|c|}
\hline \multirow[t]{2}{*}{ Botanical name } & \multirow[t]{2}{*}{ Plant part } & \multicolumn{3}{|c|}{ Linear furanocoumarins content $(\mu \mathrm{g} / \mathrm{g}) \mathrm{dry}$ weight $^{\mathrm{a}}$} \\
\hline & & 8-MOP & 5-MOP & ISOP \\
\hline Ammi majus & Seed & $3213.5 \pm 219.7$ & $717.2 \pm 6.5$ & $7537.2 \pm 1492.9$ \\
\hline Angelica archangelica & Root & $651.4 \pm 51.8$ & $392.5 \pm 208.0$ & $606.0 \pm 131.9$ \\
\hline Angelica pubescens & Root & $25.6 \pm 0.0$ & $32.5 \pm 20.0$ & $n \cdot d^{b}$ \\
\hline Apium graveolens & Seed & $21.0 \pm 4.4$ & $16.9 \pm 6.0$ & $236.5 \pm 22.4$ \\
\hline Apium graveolens & Flakes & $12.1 \pm 1.6$ & $243.2 \pm 39.7$ & $9.5 \pm 0.9$ \\
\hline Cnidium monnieri & Fruit & $707.1 \pm 78.8$ & $1788.1 \pm 152.3$ & $466.8 \pm 95.4$ \\
\hline Petroselinum crispum & Leaves & $n \cdot d^{b}$ & $34.4 \pm 10.6$ & $n \cdot d^{b}$ \\
\hline Pimpinella aniseum & Seed & $15.8 \pm 5.8$ & $n \cdot d^{b}$ & $n \cdot d^{b}$ \\
\hline Ruta graveolens & Leaves & $1342.4 \pm 135.7$ & $534.0 \pm 120.6$ & $294.9 \pm 49.5$ \\
\hline
\end{tabular}

${ }^{a}$ Results are expressed as mean $\pm S D$ from minimum three aqueous extractions.

${ }^{b}$ n. $d .=$ not detected.

study period. The participants were also asked to refrain from consuming solid foods $3.0 \mathrm{~h}$ prior to the study. The study protocol was approved by the Simon Fraser University Office of Research Ethics with approval number 2012s0565 and registration number ISRCTN83028296.

\section{Extraction of ARFP Products}

The ARFP products were extracted as per our previous study (Alehaideb et al., 2017). An ARFP product was weighed accurately and powdered in a food processor. The powders were mixed with $600 \mathrm{ml}$ of distilled water and boiled on a hot plate until half of the volume was evaporated. The aqueous extracts were filtered using a metal sieve.

\section{Dosimetry of Furanocoumarin Mixtures}

The dose measure of the furanocoumarin mixture in an ARFP extract was predicted using the concentration addition model (ATSDR, 2004; Law et al., 2017; Alehaideb et al., 2019):

$$
\text { Cmix }=\sum_{i=1}^{n} C i \times R P i
$$

Where Cmix is the effect-based dose of the furanocoumarin mixture in ARFP extract; it is expressed in $\mu \mathrm{M}$ concentration equivalents of $8-\mathrm{MOP}, \mathrm{Ci}$ is the concentration of the $i$ th furanocoumarin component in $\mu \mathrm{M}$ unit. The $\mathrm{RPi}$ (relative potency) is the $\mathrm{IC}_{50}$ of the $i$ th furanocoumarin component relative to the $\mathrm{IC}_{50}$ of 8 -MOP. The relative potency of a furanocoumarin bioactive represents an equally effective 8MOP concentration for CYP 1A2 activity inhibition. Table 2 summarizes the weights and effect-based dose measures of the ARFP products in the present study.

\section{Caffeine Pharmacokinetics in the Saliva/Plasma of Humans$$
\text { Saliva Sampling After Caffeine Administration }
$$

This study adopted a non-randomized, single-blinded, and crossover design in which each subject acted as his own control (Sheriffdeen et al., 2019). Each volunteer was supplied with a study kit containing several caffeine tablets from AdremPharma WakeUps ${ }^{\mathrm{TM}}$ (Scarborough, ON), sampling vials, and instructions to conduct the study at home. In the baseline study, each volunteer received a single oral dose of two caffeine tablets (total $200 \mathrm{mg}$ ) and saliva samples (1-2 ml) were collected at $0.5,1.0,1.5,2.0,2.5,3.0,4.0,5.0,6.0,7.0,8.0,12.0$, and $24.0 \mathrm{~h}$ post-dosing. In the ARFP extract treatment study, the same group of volunteers was used after a 4 days washout period. In this study, the volunteers consumed an ARFP extract $3.0 \mathrm{~h}$ before taking the caffeine tablets. Saliva samples were collected at 0.5 , $1.0,1.5,2.0,2.5,3.0,4.0,6.0,8.0,12.0,24.0,36.0$, and 48.0 h postdosing. All saliva samples were stored in the dark at freezing temperature until they were ready for extraction and HPLC-UV analysis.

\section{Extraction of Saliva Samples}

The saliva samples were thawed at room temperature, mixed by vortexing for $30 \mathrm{~s}$, and centrifuged for $10 \mathrm{~min}$ at $4,000 \times \mathrm{g}$. Exactly $200.0 \mu \mathrm{l}$ aliquot of the saliva sample was removed and spiked with $100.0 \mu \mathrm{l}$ of the internal standard (ISTD) benzotriazole $(50.0 \mu \mathrm{g} /$ $\mathrm{ml}$ ). The saliva samples were extracted once with $4.0 \mathrm{ml}$ ethyl acetate by vortexing for $2.0 \mathrm{~min}$ and then centrifuged at $4,000 \times g$ for $5.0 \mathrm{~min}$. The organic layer was removed and evaporated down to dryness, using a gentle stream of $\mathrm{N}_{2}$ gas. The residues were reconstituted in $150.0 \mu \mathrm{l}$ mobile-phase of the HPLC. Exactly $100.0 \mu \mathrm{l}$ aliquot of the solution was injected into the HPLCUV system.

\section{Quantifying Caffeine in Saliva Samples With HPLC-UV}

Caffeine concentrations in saliva samples were determined using a modified HPLC procedure of Perera et al. (2010). Caffeine and the benzotriazole ISTD were separated by an Agilent Zorbax XDB reverse-phase $\mathrm{C}$ - 18 column $(250 \times 4.6 \mathrm{~mm}, 5 \mu \mathrm{m}$ particle size $)$ at room temperature. Isocratic elution was performed using a solution of water: acetonitrile: acetic acid $(80: 19: 1 \mathrm{v} / \mathrm{v} / \mathrm{v})$ at a flow rate of $1.5 \mathrm{ml} / \mathrm{min}$. The UV detector was set at 280 and 580 $\mathrm{nm}$ was used as a reference wavelength. The total analysis time was $20.0 \mathrm{~min}$. The caffeine concentrations in the saliva samples were determined using a multi-level calibration curve by plotting the caffeine/benzotriazole peak area ratio against the caffeine concentration. The range of the caffeine concentration used was from $0.11-13.63 \mu \mathrm{g} / \mathrm{ml}$. The limit of detection and limit of 
TABLE 2 | The effect-based dose measures of furanocoumarin mixtures in ARFP extracts.

\begin{tabular}{lcc}
\hline Plant product name & $\begin{array}{c}\text { Weight of plant } \\
\text { product extracted }\end{array}$ & $\begin{array}{c}\text { Effect-based dose of } \\
\text { furanocoumarin mixture in } \\
\text { water extract }\end{array}$ \\
\cline { 2 - 3 } & G & $\begin{array}{c}\text { 8-MOP equiv } \\
\boldsymbol{\mu M}\end{array}$ \\
\hline P. aniseum seeds & 10.0 & 2.4 \\
P. crispum leaves & 10.0 & 3.7 \\
A. pubescens roots & 12.0 & 8.9 \\
A. graveolens seeds & 10.0 & 16.4 \\
A. graveolens flakes & 10.0 & 28.3 \\
A. archangelica roots & 4.5 & 77.1 \\
R. graveolens leaves & 3.0 & 83.4 \\
C. monnieri fruits & 3.0 & 96.7 \\
A. archangelica roots & 9.0 & 179.4 \\
A. majus seeds & 6.0 & 559.6 \\
A. majus seeds & 12.0 & 913.3 \\
\hline
\end{tabular}

quantification of the HPLC-UV method were 11.4 and $43.1 \mathrm{ng} / \mathrm{ml}$, respectively.

\section{Determination of Caffeine Pharmacokinetic Parameters}

Caffeine concentrations in the saliva samples were first converted to plasma concentrations using a 0.79 correction factor (Fuhr et al., 1993). Caffeine concentration in the plasma was plotted against the sampling time of the pharmacokinetic study with the Prism GraphPad software (San Diego, CA). The following pharmacokinetic parameters were determined: the $\mathrm{T}_{\max }$ (time to reach peak plasma level) and $\mathrm{C}_{\max }$ (concentration of peak plasma level) were determined by visual inspection. The $\mathrm{AUC}_{0 \text {-inf }}$ (area under plasma concentration-time curve from zero to infinity) was determined by non-compartmental analysis using the PK Solver software (Zhang et al., 2010). The $\mathrm{AUC}_{0 \text {-inf }}$ was determined using the log-linear trapezoidal rule from dosing time to last time point and extrapolated to infinity by dividing the last concentration with the elimination rate constant. The AUC ratio was calculated by dividing the $\mathrm{AUC}_{0 \text {-inf }}$ after ARFP extract pretreatment with the $\mathrm{AUC}_{0 \text {-inf }}$ before ARFP extract pretreatment.

\section{Inhibition of CYP 1A2-Mediated Caffeine- $N^{3}$-Demethylation in vitro Quantitation of CYP 1 A2 Inactivity}

The caffeine- $N$-demethylase assay was conducted with $\left[3^{\prime}-N-\right.$ ${ }^{14}$ C-methyl]-caffeine according to Bloomer et al. (1995) with modification by Sheriffdeen et al. (2019). Briefly, the incubation contained non-labeled caffeine $(82.0 \mu \mathrm{m}),{ }^{14} \mathrm{C}$-labeled caffeine $(0.2 \mu \mathrm{Ci})$, a furanocoumarin inhibitor (see concentrations in $I C_{50}$ Determination and Pre-incubation Time- and Furanocoumarin Concentration-dependent Inhibition of Caffeine Metabolism in vitro), NADPH $(1.34 \mathrm{~mm})$, and potassium phosphate buffer $(50.0 \mathrm{~mm}, \mathrm{pH} 7.4)$ in a final volume of $200.0 \mu \mathrm{l}$. DMSO was used to dissolve caffeine and the furanocoumarin inhibitor; less than $1 \%$ incubation volume of DMSO was found to have no significant effect on caffeine 3-N-demethyation activity. Incubation was conducted at $37^{\circ} \mathrm{C}$ in a metabolic incubator with a 60 cycles/min shaking rate. At the conclusion of $10 \mathrm{~min}$ incubation, the reaction was terminated by the addition of $10 \%$ TCA solution $(50.0 \mu \mathrm{l})$. The incubation mixture was centrifuged at $4,000 \times g$. An aliquot $(300.0 \mu \mathrm{l})$ of the supernatant was applied to a $3.0 \mathrm{ml}$ Sigma-Aldrich Superclean ENVI-Carbon solid phase extraction (SPE) tube (0.25 g, 80-100 mesh). Demethylated metabolites of caffeine (i.e., ${ }^{14} \mathrm{C}$-formaldehyde and ${ }^{14} \mathrm{C}$-formic acid) were eluted from the SPE tube with $2.0 \mathrm{ml}$ of water. The eluant was collected into a scintillation vial. After the addition of $15.0 \mathrm{ml}$ scintillation cocktail, the radioactivity in the vial was counted in a liquid scintillation counter. The results were expressed as residual counts of the control incubation.

\section{$\mathrm{IC}_{50}$ Determination}

In vitro caffeine- $N$-demethylase activity was determined with various concentrations of a furanocoumarin inhibitor: $0.01-11.12 \mu \mathrm{m}$ for 8 -MOP; $0.06-7.10 \mu \mathrm{m}$ for $5-\mathrm{MOP}$; and $0.01-38.45 \mu \mathrm{m}$ for ISOP. CYP $1 \mathrm{~A} 2$ activity inhibition was plotted against $\log$ furanocoumarin concentration after normalizing the inhibition data from $0-100 \%$. The resulting inhibition-concentration curves were fitted separately to a four-parameter logistic function to determine the $\mathrm{IC}_{50}$ values. Curve fitting was performed using the GraphPad Prism version 5.04 (GraphPad Software, San Diego, CA). The $\mathrm{IC}_{50}$ represented the concentration of the furanocoumarin chemical to evoke a half maximal inhibition of the CYP $1 \mathrm{~A} 2$ activity.

\section{Pre-incubation Time- and Furanocoumarin Concentration-dependent Inhibition of Caffeine Metabolism in vitro}

These studies were conducted in two steps: pre-incubation with a furanocoumarin inactivator followed by dilution and incubation to measure the caffeine metabolizing activity. In the preincubation step, HLMs $(1.2 \mathrm{mg} / \mathrm{ml})$ were pre-incubated with different furanocoumarin concentrations in the presence of $\mathrm{NADPH}$ for various time periods at $37^{\circ} \mathrm{C}$. The pre-incubation times of the studies were: $0.5,1.0,1.5$, and $2.0 \mathrm{~min}$ for 8 -MOP and $5-\mathrm{MOP}$, and $0.5,1.0,2.0$, and $3.0 \mathrm{~min}$ for ISOP. The furanocoumarin concentration ranges of the studies were: $1.07-17.14 \mu \mathrm{m}$ for 8 -MOP. $1.13-18.07 \mu \mathrm{M}$ for $5-\mathrm{MOP}$, and 0.47-15.02 for ISOP. In the final incubation step, $32.0 \mu \mathrm{l}$ of the pre-incubation mixture was transferred to an incubation vial containing fresh NADPH $(1.0 \mathrm{~mm})$, non-labeled caffeine $(6.4 \mu \mathrm{m})$, and ${ }^{14} \mathrm{C}$-caffeine $(0.2 \mu \mathrm{Ci})$. The final incubation volume was $320.0 \mu \mathrm{l}$. At the conclusion of a $10 \mathrm{~min}$ incubation, the reaction was stopped by the addition of a $10 \%$ TCA solution. The incubation mixture was extracted by a SPE tube, and the radioactivity in the eluant was counted in a liquid scintillation counter as described earlier.

The observed in vitro rate constant $\left(\mathrm{k}_{\mathrm{obs}}\right)$ was calculated using the slopes of linear regression analyses from natural logarithm (Ln) percentage remaining activity against pre-incubation time plots. The maximum inactivation rate constant $\left(\mathrm{k}_{\text {inact }}\right)$ was calculated using the non-linear regression analyses of plots of the inactivator concentrations against $\mathrm{k}_{\mathrm{obs}}$ values. The inactivator concentration $\left(\mathrm{K}_{\mathrm{I}}\right)$ was extrapolated at $50 \% \mathrm{k}_{\text {inact }}$ value. The plotting was performed using the GraphPad Prism version 5.04 (GraphPad Software, San Diego, CA). 


\section{Irreversible Binding of ${ }^{14} \mathrm{C}-8-\mathrm{MOP}-$ Derived Radioactivity to HLMs}

These studies were conducted as per Jollow et al. (1973) with modification (Law and Chakrabarti, 1983; Law and Meng, 1996). The complete or control incubation mixture consisted of HLMs (1.0 mg), ${ }^{14} \mathrm{C}-8$-MOP $(0.2 \mu \mathrm{Ci})$, potassium phosphate buffer $(50.0 \mathrm{~mm}, \mathrm{pH} 7.4)$, and NADPH $(1.0 \mathrm{~mm})$ in a $1.34 \mathrm{ml}$ final incubation volume. The incubation mixture was pre-warmed at $37^{\circ} \mathrm{C}$ for $5.0 \mathrm{~min}$ and the reaction was started with the addition of HLMs. After a $10 \mathrm{~min}$ incubation, the reaction was terminated by the addition of ice-cold 10\% TCA solution. Unchanged ${ }^{14} \mathrm{C}-8$ MOP and water-soluble metabolites in the incubation were washed off repeatedly with three cycles each of methanol, acetonitrile, and acetone. Our preliminary studies indicated that the three-cycle solvent washes were sufficient to remove all unbound radioactivity from the precipitates of HLMs. The ${ }^{14} \mathrm{C}$ bound to the protein precipitates was determined using a liquid scintillation counter after the addition of $15.0 \mathrm{ml}$ scintillation cocktail. The effects of different incubation conditions on ${ }^{14} \mathrm{C}$-adducts formation were studied by omitting $\mathrm{NADPH}$ cofactor, depleting $\mathrm{O}_{2}$, adding $\mathrm{CO}$ or using heated HLMs in the complete incubation mixture.

\section{Statistical Analysis}

The data were analyzed using the Student's paired $t$-test, twotailed and 95\% confidence interval using Microsoft Excel. The difference between two comparable data sets were considered significant when $p \leq 0.05$.

\section{RESULTS}

\section{Caffeine and Furanocoumarin Bioactive in Saliva Samples}

Figure 2 shows a typical HPLC chromatogram of caffeine and benzotriazole ISTD in the saliva extract. Little or no caffeine was detected in the saliva samples before the human volunteers consumed the caffeine tablets. Neither furanocoumarin bioactive nor unknown phytochemicals were found in the saliva samples after the volunteers were treated with an ARFP extract.

\section{Caffeine Pharmacokinetics in Human Volunteers Before and After Pre-treatment With an ARFP Extract}

Figure 3A displays the time course of caffeine concentration in the plasma of human volunteers before and after pre-treatment with an aqueous extract of $A$. majus seeds, $A$. archangelica roots, C. monnieri fruits or R. graveolens leaves. Caffeine concentrations in the plasma were found to increase significantly after each ARFP extract pre-treatment as seen in Figure 3A. Table 3 summarizes the pharmacokinetic parameters of the concentration-time curves. Pre-treatment of humans with $A$. majus seeds extract significantly increased the $\mathrm{AUC}_{0 \text {-inf }}$ of caffeine by $432 \%$, the $\mathrm{T}_{\max }$ from 0.8 to $2.4 \mathrm{~h}$, and the $\mathrm{C}_{\max }$ by $16.6 \%$. A. archangelica roots extract pre-treatment increased the

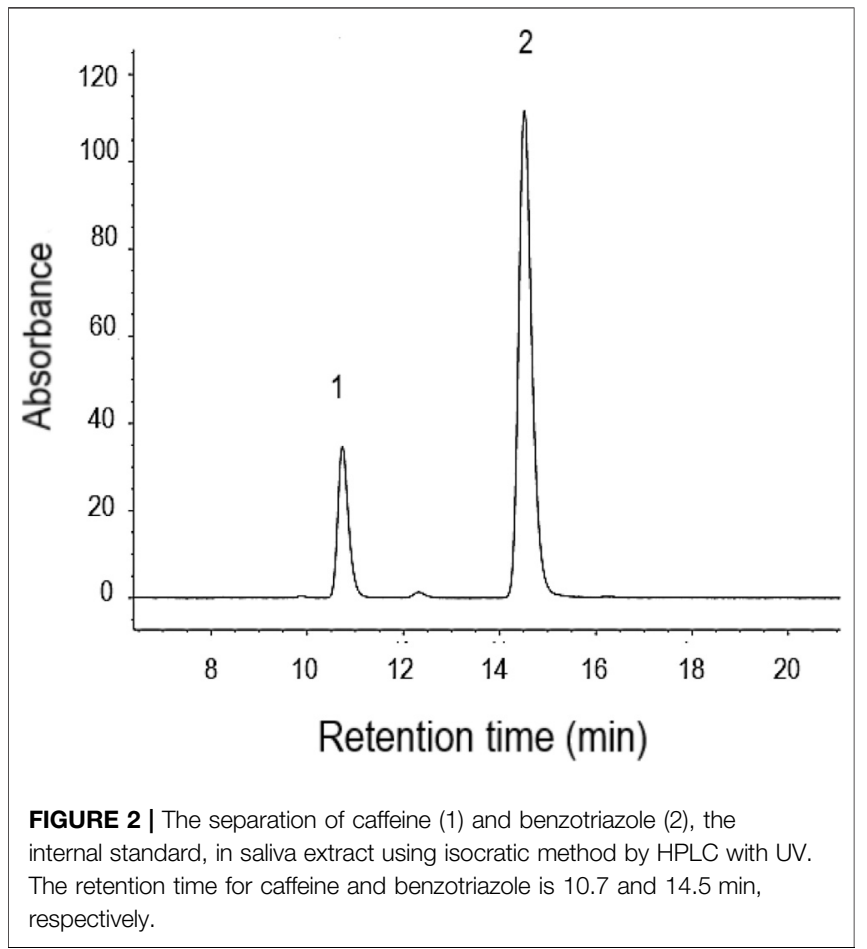

AUC $_{0 \text {-inf }}$ of caffeine by $232 \%$, the $\mathrm{T}_{\max }$ from 0.8 to $1.3 \mathrm{~h}$, and no change for $\mathrm{C}_{\max }$ value. If $2 \mathrm{x}$ weights of $A$. majus seeds and $A$. archangelica roots were used in the extraction (Table 3 bottom rows), the $\mathrm{AUC}_{0 \text {-inf }}$ of caffeine increased by 577 and $267 \%$, respectively. For $A$. archangelica $2 \mathrm{x}$, the double-dose delayed $\mathrm{T}_{\max }$ and increased $\mathrm{C}_{\max }$ about $47 \%$. Not much change for $A$. majus seeds double-dose in comparison to the less dose. $C$. monnieri fruits extract increased the $\mathrm{AUC}_{0 \text {-inf }}$ of caffeine by $220 \%, \mathrm{~T}_{\max }$ from 0.7 to $1.8 \mathrm{~h}$ but had no effect on the $\mathrm{C}_{\max }$ whereas $R$. graveolens leaves extract pre-treatment increased the $\mathrm{AUC}_{0 \text {-inf }}$ of caffeine by $135 \%$, the $\mathrm{T}_{\text {max }}$ from 0.6 to $1.0 \mathrm{~h}$, and the $\mathrm{C}_{\max }$ by $12 \%$. Interestingly, the clearance $(\mathrm{CL})$ of caffeine was decreased significantly after pre-treating the volunteers with these plant extracts. Thus, pre-treatment of humans with one of these 4 ARFP extracts resulted in an increase in caffeine $\mathrm{AUC}_{0}$ inf with a concomitant decrease in CL, a finding which clearly showed these ARFP extracts were potent inhibitors of caffeine metabolism.

Figure 3B shows the time course of caffeine concentration in the plasma of volunteers before and after they were pre-treated with an extract of $A$. pubescens roots, A. graveolens seeds, $A$. graveolens flakes, $p$. aniseum seeds, or $p$. crispum leaves. Pretreatment of human volunteers with the remaining 5 ARFP extracts did not change the concentration-time profiles of caffeine significantly. Table 4 summarizes the pharmacokinetic parameters of the caffeine concentration-time curves in these studies. Pre-treatment of humans with A. graveolens seeds extract increased the $\mathrm{AUC}_{0 \text {-inf }}$ of caffeine by $12 \%$, the $\mathrm{T}_{\max }$ from 0.7 to $1.2 \mathrm{~h}$, but the $\mathrm{C}_{\max }$ was reduced by $8.2 \%$ but the increase in $\mathrm{AUC}_{0 \text {-inf }}$ was statistically insignificant compared to the untreated volunteers. The pre-treatment with A. graveolens flakes 
TABLE 3 | Caffeine pharmacokinetic parameters in human volunteers before and after pre-treatment with the aqueous extract of $A$. majus, $A$. archangelica, $C$. monnieri, or $R$. graveolens. The $\pm \mathrm{SD}$ of the data is omitted for better display and comparison.

\begin{tabular}{|c|c|c|c|c|c|c|c|c|c|}
\hline \multirow[t]{3}{*}{ Plant product name } & \multirow[t]{3}{*}{$n^{a}$} & \multicolumn{2}{|c|}{$\mathbf{T}_{\max }$} & \multicolumn{2}{|c|}{$\mathrm{C}_{\max }$} & \multicolumn{2}{|c|}{$A C_{0-i n f}$} & \multicolumn{2}{|c|}{ CL } \\
\hline & & \multicolumn{2}{|c|}{$\mathbf{H}$} & \multicolumn{2}{|c|}{$\mu \mathrm{g} / \mathrm{ml}$} & \multicolumn{2}{|c|}{$\mu g / m l^{\star} h$} & \multicolumn{2}{|c|}{$\mathrm{ml} / \mathrm{min}$} \\
\hline & & $\mathbf{U T}^{\mathbf{b}}$ & $\mathbf{T}^{\mathbf{b}}$ & UT & $\mathbf{T}$ & UT & $\mathbf{T}$ & UT & $\mathbf{T}$ \\
\hline A. majus seeds & 6 & 0.8 & 2.4 & 5.4 & $6.3^{c}$ & 40.4 & $174.6^{d}$ & 95.6 & $21.7^{\mathrm{d}}$ \\
\hline C. monnieri fruits & 5 & 0.7 & $1.8^{d}$ & 6.0 & 5.9 & 46.1 & $101.8^{c}$ & 85.2 & $40.5^{d}$ \\
\hline R. graveolens leaves & 6 & 0.6 & 1.0 & 6.6 & 7.4 & 50.9 & $68.6^{c}$ & 82.1 & 60.4 \\
\hline A. archangelica roots & 6 & 0.8 & $1.3^{d}$ & 5.4 & 5.4 & 43.3 & $100.3^{d}$ & 84.9 & $44.8^{d}$ \\
\hline A. majus seeds ${ }^{e}$ & 2 & 0.5 & 2.5 & 5.0 & 6.8 & 34.2 & $197.4^{c}$ & 116.7 & 17.1 \\
\hline A. archangelica roots ${ }^{\mathrm{e}}$ & 4 & 0.8 & 2.8 & 5.1 & 7.5 & 46.5 & $124.3^{d}$ & 90.5 & 28.8 \\
\hline
\end{tabular}

${ }^{a} \mathrm{n}$ is the number of human volunteers in the study.

${ }^{b} U T=$ untreaed human volunteers, $T=$ human volunteers pretreated by an aqueous extract.

${ }^{c}$ Significantly different to untreated human volunteer $(0.01<\mathrm{p} \leq 0.05)$.

${ }^{d}$ Significantly different to untreated human volunteer $(\mathrm{p} \leq 0.01)$.

${ }^{e}$ Double-dose of the $A$. majus seeds and $A$. archangelica roots presented before.

TABLE 4 | Caffeine pharmacokinetic parameters of human volunteers before and after pre-treatment with the water extract of $P$. aniseum, $P$. crispum, $A$. pubescens, $A$. graveolens seeds, or $A$. graveolens flakes. The \pm SD of the data is omitted for better display and comparison.

\begin{tabular}{|c|c|c|c|c|c|c|c|c|c|}
\hline \multirow[t]{3}{*}{ Plant product name } & \multirow[t]{3}{*}{$n^{a}$} & \multicolumn{2}{|c|}{$\mathbf{T}_{\max }$} & \multicolumn{2}{|c|}{$\mathbf{C}_{\max }$} & \multicolumn{2}{|c|}{ AUC $_{0 \text {-inf }}$} & \multicolumn{2}{|c|}{ CL } \\
\hline & & \multicolumn{2}{|c|}{$\mathbf{H}$} & \multicolumn{2}{|c|}{$\mu \mathrm{g} / \mathrm{ml}$} & \multicolumn{2}{|c|}{$\mu \mathrm{g} / \mathrm{ml}^{\star} h$} & \multicolumn{2}{|c|}{$\mathrm{ml} / \mathrm{min}$} \\
\hline & & $\mathbf{U T}^{\mathbf{b}}$ & $\mathbf{T}^{\mathbf{b}}$ & UT & $\mathbf{T}$ & UT & $\mathbf{T}$ & UT & $\mathbf{T}$ \\
\hline A. graveolens flakes & 4 & 0.8 & 1.5 & 5.4 & 5.4 & 50.1 & 52.2 & 73.5 & 67.7 \\
\hline A. graveolens seeds & 6 & 0.7 & 1.2 & 6.1 & 5.6 & 42.9 & 48.2 & 91.3 & 74.7 \\
\hline A. pubescens roots & 5 & 2.4 & 3.1 & 5.0 & 2.9 & 33.5 & 23.6 & 160.3 & 141.4 \\
\hline P. crispum leaves & 4 & 1.2 & 1.1 & 6.0 & 6.3 & 53.0 & 73.1 & 78.0 & 56.3 \\
\hline P. aniseum seeds & 6 & 0.6 & 1.1 & 6.5 & 5.4 & 55.8 & 54.0 & 77.9 & 76.4 \\
\hline
\end{tabular}

${ }^{a} \mathrm{n}$ is the number of human volunteers in the study.

${ }^{b} U T=$ untreaed human volunteers, $T=$ human volunteers pretreated by an aqueous extract.

extract increased the mean $\mathrm{T}_{\max }$ of caffeine from 0.8 to $1.5 \mathrm{~h}$, but

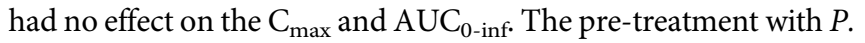
aniseum seeds extract increased the $\mathrm{T}_{\max }$ of caffeine from 0.6 to $1.1 \mathrm{~h}$, reduced the $\mathrm{C}_{\max }$ by $16.9 \%$, and had no effect on the $\mathrm{AUC}_{0-}$ inf. The pre-treatment with P. crispum leaves increased the $\mathrm{AUC}_{0-}$ inf of caffeine by $27.5 \%$ but the increase was statistically insignificant. P. crispum leaves pre-treatment also increased the $\mathrm{C}_{\max }$ of caffeine by $5.0 \%$ but had no effect on the $\mathrm{T}_{\max }$. Interestingly, treatment with $A$. pubescens roots decreased AUC $_{0 \text {-inf }}$ by $30.0 \%$ and $\mathrm{C}_{\max }$ by $40 \%$ but both were found not significant $(p>0.05)$. However, treatment with $A$. pubescens roots increased Tmax from 2.4 to $3.1 \mathrm{~h}$. In contrast, the CL of caffeine in these studies was decreased after ARFP pre-treatment. Thus, none of the pharmacokinetic parameters, with the exception of CL for A. pubescens roots treatment ( $p$ value 0.04 ), was changed significantly after the volunteers were pre-treated with these 5 ARFP extracts.

Figure 4 depicts the relationship between caffeine AUC ratio and the effect-based dose measure of the 8-MOP, 5-MOP and ISOP mixture in the ARFP extract. Caffeine AUC ratio correlated linearly with the effect-based dose of the furanocoumarin mixture $\left(R^{2}=0.94\right)$. Thus, A. majus seeds, $A$. archangelica roots, $C$. monnieri fruits, and $R$. graveolens leaves, which had large effect-based dose measures and were potent caffeine metabolism inhibitors, were located at the upper part of the straight line. The remaining ARFP products which were less potent inhibitors and had small effect-based dose measures, were located at the lower part of the straight line. In other words, the extent of CYP 1A2 inhibition is determined by the additive combination effects of just 3 furanocoumarin bioactive (i.e., 8-MOP, 5-MOP, and ISOP) in the ARFP extract.

\section{In Vitro Inactivation of Microsomal Caffeine- $N$-Demethylation Activity by Individual Furanocoumarin Chemicals}

Little or no caffeine was metabolized by the HLMs if NADPH were omitted from the incubation (data not shown). Caffeine- $N$ demethylase activity was significantly inhibited when 8-MOP, 5MOP, or ISOP was added to the incubation. Also, caffeine- $N$ demethylase activity appeared to decrease with an increasing furanocoumarin concentration in the incubation. Figure 5 shows the inhibition- $\log _{10}$ concentration curves of 8-MOP, 5-MOP, and ISOP on caffeine metabolism. The inhibition-concentration curves were parallel to one another, indicating the linear furanocoumarins and caffeine were bound to similar metabolic sites on the CYP $1 \mathrm{~A} 2$ isozyme. The $\mathrm{IC}_{50}$ of 8-MOP, 5-MOP, and ISOP on caffeine metabolism were determined to be $0.09 \pm 0.05$, $0.13 \pm 0.11$, and $0.29 \pm 0.22 \mu \mathrm{m}$ (mean \pm standard deviation 


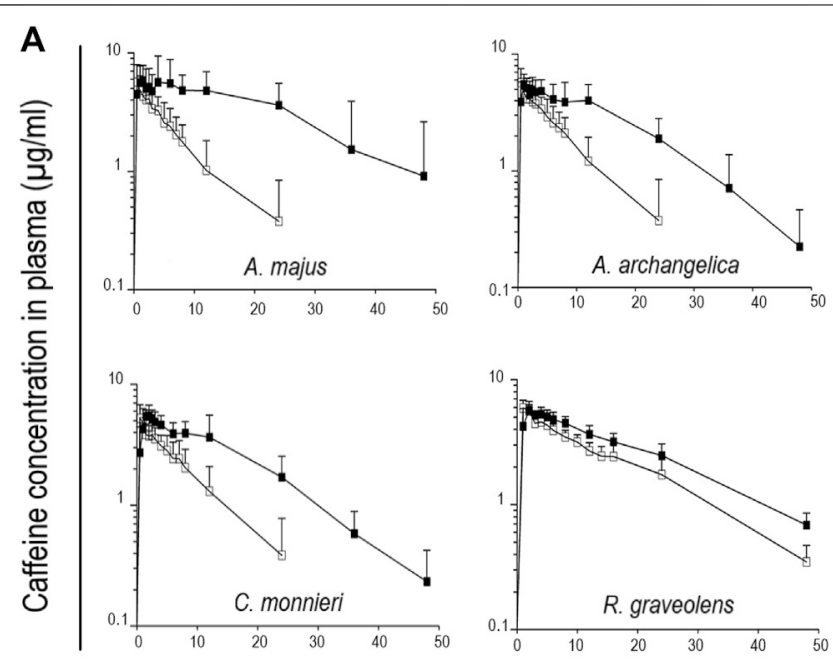

Post-dosing time (h)

\section{B}

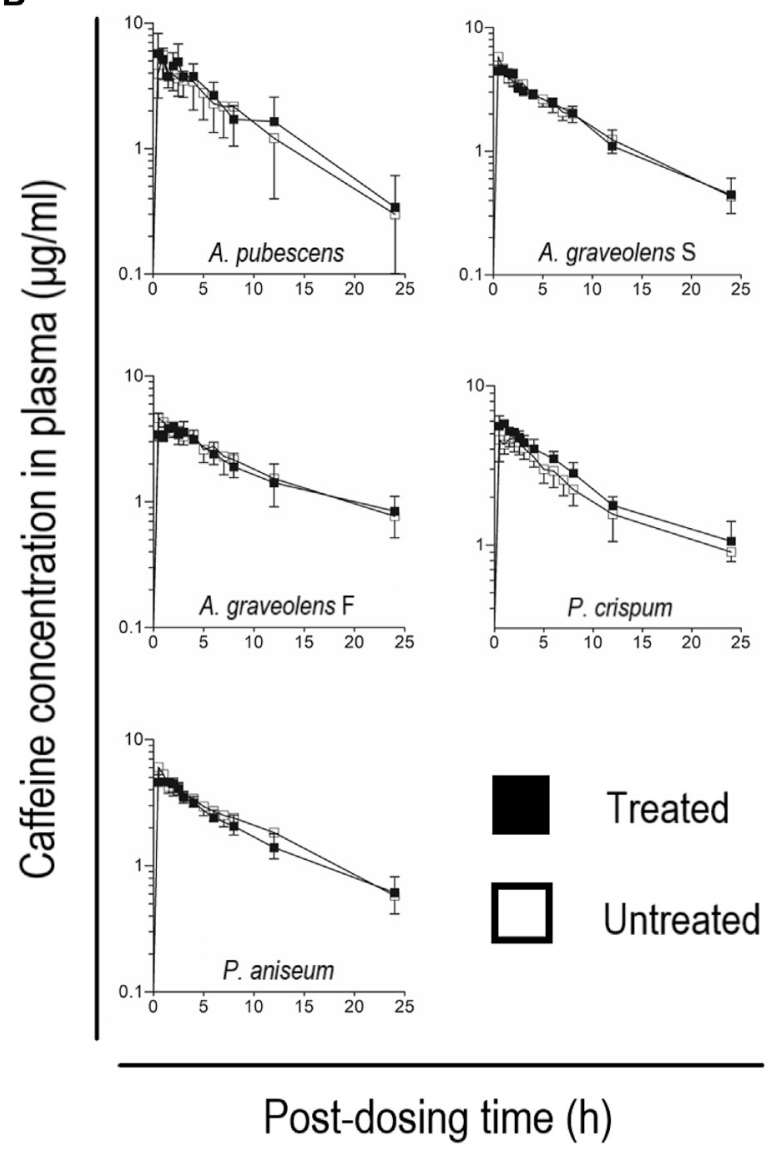

FIGURE 3 | (A) Time course of caffeine concentration in the plasma of volunteers before and after pre-treatment with an extract of $A$. majus, $A$. archangelica, $C$. monnieri, and $R$. graveolens. Each point is plotted as mean \pm SD. Empty squares represent caffeine concentrations in volunteers with no ARFP extract pre-treatment. Filled squares represent caffeine concentrations in volunteers with ARFP extract pre-treatment $3.0 \mathrm{~h}$ before receiving the caffeine tablets. (B) Time course of caffeine concentrations in the plasma of volunteers before and after pre-treatment with an extract of $P$. aniseum, $P$. crispum, A. pubescens, $A$. graveolens seeds, and $A$. graveolens flakes. The point is reported as mean \pm SD. Empty squares represent caffeine concentrations in volunteers with no ARFP extract pre-treatment. Filled squares represent caffeine concentrations in volunteers with ARFP extract pre-treatment $3.0 \mathrm{~h}$ before receiving the caffeine tablets. 


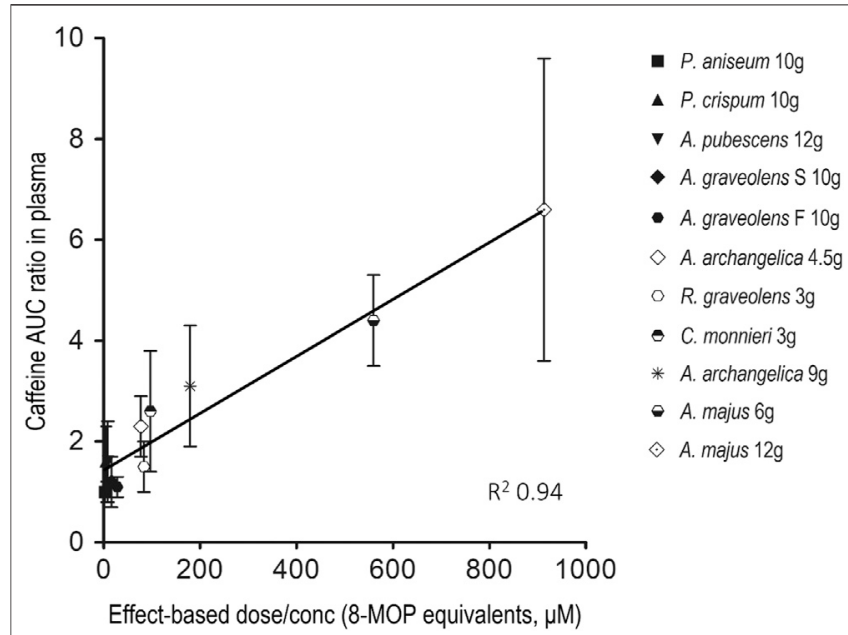

FIGURE 4 | Correlation between the area-under-the-concentrationtime-curve (AUC) ratio of caffeine and the effect-based dose measure of the furanocoumarin mixture in ARFP extract. The data represent mean \pm SD of caffeine AUC ratio with different effect-based dose measures in the ARFP extracts.

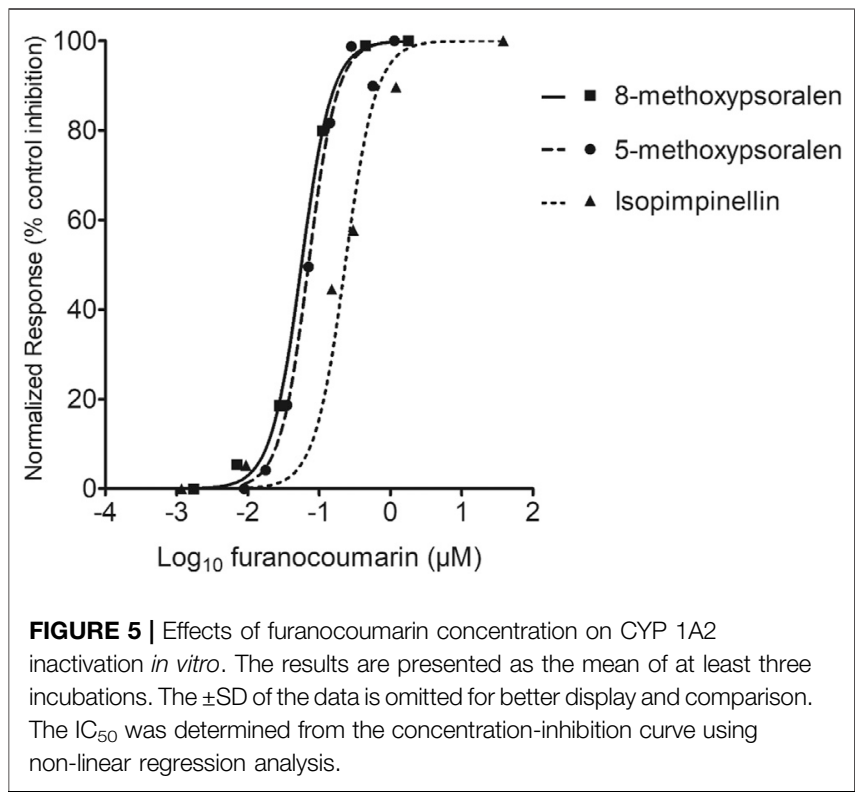

(SD)), respectively. Thus, the inhibition potency of the furanocoumarin bioactive decreased in the order of 8-MOP > 5 -MOP > ISOP. The $\mathrm{IC}_{50}$ values were used to calculate a relative potency (or inhibitory equivalence factor) for the furanocoumarin bioactive in the ARFP extracts. The inhibitory equivalence factor for 8-MOP, 5-MOP, and ISOP were 1.00, 0.69, and 0.31 , respectively, assuming the $8-\mathrm{MOP}$ value was equal to 1.00. The effect-based dose for the furanocoumarin mixture in an ARFP extract was predicted using the concentration addition model. Table 2 summarizes the ARFP product weights used in the extraction and the corresponding effect-based dose measures of the furanocoumarin mixture in the present study.
TABLE 5 | The effects of different incubation conditions on the amounts of irreversibly bound radioactivity formed in human liver microsomes.

Incubation mixture

\begin{tabular}{c}
$\begin{array}{c}\text { Irreversible } \\
\text { bound 8-MOP-derived }{ }^{\mathbf{1 4}} \mathbf{C}^{\mathbf{a}}\end{array}$ \\
\hline $\begin{array}{c}\text { (pmol } \\
\text { per } \mathbf{m g} \text { protein) }\end{array}$ \\
$3.67 \pm 0.39$ \\
$0.43 \pm 0.03^{\mathrm{b}}$ \\
$0.51 \pm 0.14^{\mathrm{b}}$ \\
$2.66 \pm 0.44^{\mathrm{b}}$ \\
$2.58 \pm 1.06^{\mathrm{b}}$
\end{tabular}

performed for each experiment.

${ }^{b}$ Significantly different to control $(p \leq 0.05)$.

Figure 6A shows the effects of pre-incubation time and furanocoumarin concentration on CYP $1 \mathrm{~A} 2$ inactivation. The degree of caffeine metabolism inhibition was time- and concentration-dependent, indicating involvement of the irreversible inhibition mechanism. Figure 6B shows the nonlinear relationship between $\mathrm{k}_{\mathrm{obs}}$ and the concentration of individual furanocoumarin in these studies. The $\mathrm{K}_{\mathrm{I}}$ values for 8-MOP, 5-MOP, and ISOP were estimated at $0.78 \pm 0.32,3.73 \pm$ 3.66 , and $4.48 \pm 0.56 \mu \mathrm{m}$, respectively. The estimated $\mathrm{k}_{\text {inact }}$ values were $0.17 \pm 0.01,0.35 \pm 0.12$, and $0.65 \pm 0.03 \mathrm{~min}^{-1}$, respectively.

The proposed irreversible inhibition mechanism was studied further with ${ }^{14} \mathrm{C}-8$-MOP metabolism studies. ${ }^{14} \mathrm{C}-8$-MOP biotransformation in NADPH-fortified HLMs resulted in the formation of ${ }^{14} \mathrm{C}$-adducts which were studied using different incubation conditions. Table 5 shows little or no ${ }^{14} \mathrm{C}$-adducts were formed when boiled HLMs were used or NADPH and $\mathrm{O}_{2}$ were omitted in the incubation. An increase of the $\mathrm{CO}$ concentration in the incubation decreased the amounts of ${ }^{14} \mathrm{C}$-adducts formed. These results indicated that ${ }^{14} \mathrm{C}-8$-MOP reactive metabolite(s) was formed and bound irreversibly to the HLMs during ${ }^{14} \mathrm{C}-8$-MOP biotransformation.

\section{DISCUSSION}

Our results show all nine tested ARFP products are able to inhibit caffeine metabolism in humans to some extent (Figures $\mathbf{3 A}, \mathbf{B}$; Tables 3, 4). These findings are consistent with previous reports that caffeine and linear furanocoumarins are metabolized by the same hepatic CYP 1A2 isozyme. The A. majus, A. archangelica, $C$. monnieri, and R. graveolens, are the most potent inhibitors among the tested products since they can alter the pharmacokinetics of caffeine in humans by increasing the AUC ratio of caffeine with a concomitant decrease in CL (Table 3).

A range of AUC values $\left(33.5-55.8 \mu \mathrm{g} / \mathrm{ml}{ }^{\star} \mathrm{h}\right)$ is observed in the untreated or control volunteers in our study (Tables 3, 4). The wide AUC range values probably are due to the inter- and intraindividual differences in caffeine pharmacokinetics (Tian et al., 2019). As such, a comparison of AUC values between our and other studies would render additional confidence in our results. The mean \pm SD caffeine AUC value in healthy volunteers after 


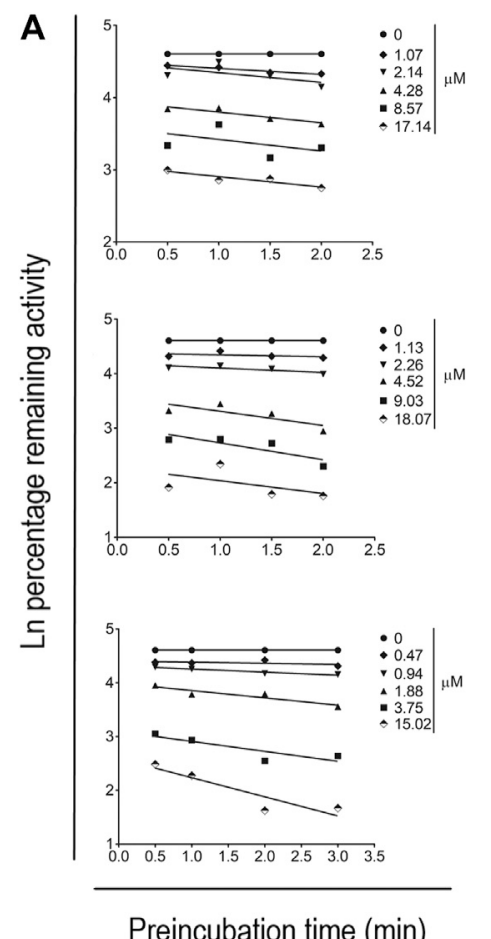

B

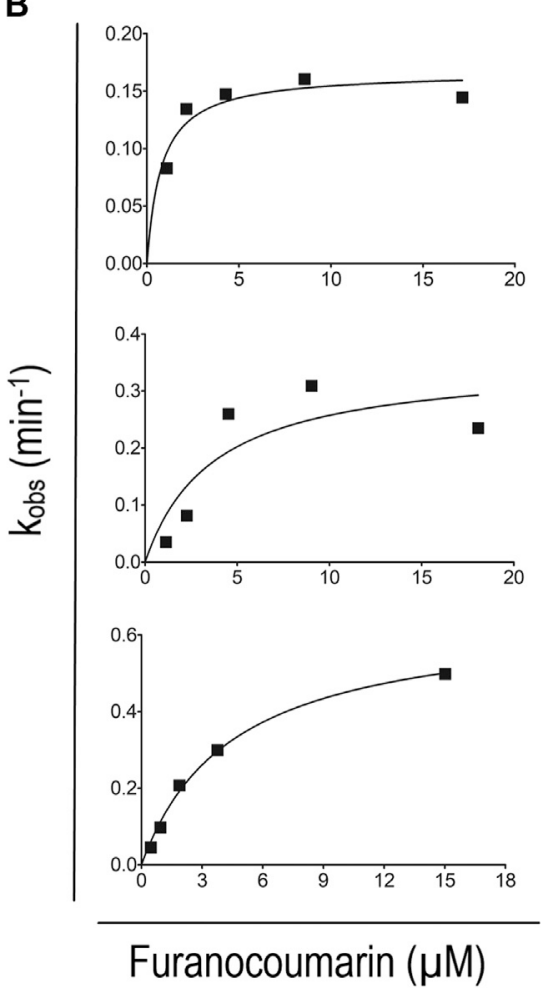

FIGURE 6 | (A) Time- and concentration-dependent inactivation of CYP 1A2 activity by 8-MOP (upper), 5-MOP (middle) and ISOP (lower). The results are presented as the mean of at least three independent incubations. The \pm SD of the data is omitted for better display and comparison. (B) Maximum inactivation rate of CYP 1 A2 activity by 8-MOP (upper), 5-MOP (middle) and ISOP (lower). The results are presented as the mean of at least three independent incubations. The $\pm \mathrm{SD}$ of the data is omitted for better display and comparison. receiving a $5 \mathrm{mg} / \mathrm{kg}$ dose is $60.8 \pm 23.7 \mu \mathrm{g} / \mathrm{ml}{ }^{\star} \mathrm{h}$ (Kamimori et al., 1995). This is very close to the high values in our AUC range (Tables 3,4$)$ ). In contrast, an AUC value of $28.5 \pm 14.9 \mu \mathrm{g} / \mathrm{ml}{ }^{\star} \mathrm{h}$ is reported for 12 human volunteers after receiving $167 \mathrm{mg}$ of caffeine orally (Fuhr et al., 1993). This is comparable to the low values in our AUC range.

The AUC ratio of caffeine in human volunteers correlates linearly with the effect-based dose of the furanocoumarin mixture administered (Figure 4). The linear dose-inhibition relationship indicates that the degree of caffeine metabolism inhibition is dependent mainly on the additive combination effects (or the effect-based dose) of three linear furanocoumarins (i.e., 8-MOP, 5-MOP, and ISOP) in the ARFP products although other known and/or unknown phytochemicals also may participate in caffeine metabolism inhibition. For example, the apigenin in P. crispum (Meyer et al., 2006) and the osthole in A. pubescens (Ko et al., 1989) have been shown to be inhibitors of CYP 1A2 activity (Peterson et al., 2006; Yang et al., 2012). However, because of the linear dose-inhibition relationship and the high correlation coefficient, it is unlikely apigenin, osthole or an unknown phytochemical plays an important role in caffeine metabolism inhibition.

The inhibitory effects of ARFP products appear to last for a relatively long time since the ARFP extract is administered to the human volunteers $3.0 \mathrm{~h}$ prior to caffeine consumption (see Saliva Sampling After Caffeine Administration.). The long inhibitory effects of ARFP products are consistent with the following studies: Firstly (Mays et al., 1987), have shown humans dosed with methoxsalen (or 8-MOP) $1.0 \mathrm{~h}$ before are still able to inhibit caffeine metabolism. Secondly, the furanocoumarin bioactive in ARFP products can destroy CYP $1 \mathrm{~A} 2$ isozyme because they are irreversible inhibitors. Since the only means for the CYP $1 \mathrm{~A} 2$ to regain its activity is by isozyme re-synthesis, it would take a long time. Thirdly, the timing of ARFP inhibition and the $T_{\max }$ of individual furanocoumarins overlap one another. For example, the mean $\mathrm{T}_{\max }$ of 8-MOP in Psoralen and Ultraviolet A (PUVA) patients is reported to range from $0.6 \pm 0.2 \mathrm{~h}$ to $2.3 \pm 0.9 \mathrm{~h}$ (Siddiqui et al., 1984). In another study, the mean $\mathrm{T}_{\max }$ of 8 -MOP in PUVA patients ranges from $0.9 \pm 0.4 \mathrm{~h}$ to $2.0 \pm 0.6 \mathrm{~h}$ (Walther et al., 1992). The $\mathrm{T}_{\max }$ of 5-MOP in healthy humans and PUVA patients are $3.0 \pm 0.6 \mathrm{~h}$ (Stolk et al., 1981) and $2.8 \pm 0.8 \mathrm{~h}$ (Shephard et al., 1999), respectively. Although we are unable to find the $\mathrm{T}_{\max }$ of ISOP in humans, the $\mathrm{T}_{\max }$ of ISOP in rats after receiving an oral dose of the Toddalia asiatica $\mathrm{L}(\mathrm{Lam})$ and $C$. monnieri herbal products are shown to be $1.3 \pm 0.3 \mathrm{~h}$ (Liu et al., 2012) and $1.1 \pm 0.3 \mathrm{~h}$ (Li et al., 2014), respectively.

The inhibition-concentration curves for pure 8-MOP, 5-MOP, and ISOP chemicals are parallel to one another (Figure 5). Villeneuve et al. (2000) have shown that parallelism in the inhibition-concentration curves is a pre-requisite to determine an accurate relative potency for the CYP inhibitors. In the present study, the $\mathrm{IC}_{50}$ of 8 -MOP, 5-MOP, and ISOP on caffeine metabolism are $0.09,0.13$, and $0.29 \mu \mathrm{m}$, respectively. In contrast, the $\mathrm{IC}_{50}$ of $8-\mathrm{MOP}, 5-\mathrm{MOP}$, and ISOP on ethoxyresorufin-O-deethylase activity are 9.6, 2.3, and $1.9 \mu \mathrm{m}$, respectively in mice liver microsomes (Cai et al., 1993). The $\mathrm{IC}_{50}$ of 8-MOP on 7-ethoxycoumarin deethylase and benzo(a)pyrene 
hydroxylase activities are about $25 \mu \mathrm{m}$ in HLMs (Tinel et al., 1987). An explanation for the discrepancy in results between our and other studies is not readily available but is likely related to the different animal species, amounts of microsomal proteins, choice of probe substrates, and detection methods used in the studies. Nevertheless, because of the parallel inhibition-concentration curves, we are confident that the $\mathrm{IC}_{50}$ and the derived relative potency are determined accurately.

In vitro CYP $1 \mathrm{~A} 2$ inactivation by individual furanocoumarins is pre-incubation time- and furanocoumarin concentrationdependent (Figures 6A,B) which are the characteristics of the irreversible or mechanism-based inhibition mechanism. Our proposed inhibition mechanism is consistent with the following publications: 1) the ISOP is a mechanism-based inhibitor of human CYP $1 \mathrm{~A} 2$ isozyme with $\mathrm{K}_{\mathrm{I}}$ and $\mathrm{k}_{\text {inact }}$ values of $1.2 \mu \mathrm{m}$ and $0.34 \mathrm{~min}^{-1}$ respectively (Kang et al., 2011), 2) the 8-MOP is a time-dependent, suicide inhibitor for the CYP enzymes of mice and rats (Folin-Fortunet et al., 1986; Letteron et al., 1986; Mays et al., 1990). Also, 8-MOP is a timedependent inhibitor of CYP 2A6 enzyme in humans (Koenigs et al., 1997), 3) the 5-MOP is capable of inactivating CYP enzymes in rats (Fuhr et al., 1993), and 4) (Folin-Fortunet et al., 1986) have proposed a dual mechanism of competitive inhibition and irreversible inhibition with the latter being the dominant mechanism to explain CYP enzyme inactivation by methoxsalen in the rat.

The removal of NADPH or the reduction of $\mathrm{O}_{2}$ level in the incubation results in decreased formation of ${ }^{14} \mathrm{C}$-adducts (Table 5). These results indicate ${ }^{14} \mathrm{C}-8$-MOP biotransformation is mediated by an oxidation reaction of HLMs and ${ }^{14} \mathrm{C}$-adducts are the by-products of ${ }^{14} \mathrm{C}-8$-MOP metabolism. We hypothesize the formation of ${ }^{14} \mathrm{C}$-adducts to involve the following steps: the furan ring of ${ }^{14} \mathrm{C}-8-\mathrm{MOP}$ is first oxidized by CYP $1 \mathrm{~A} 2$ to an electrophilic epoxide intermediate(s) which then binds irreversibly to the CYP 1A2-substrate complex and inactivates the CYP 1A2 isozyme itself. Our hypothesis is supported by the reports that 8 -MOP is metabolized by epoxidation of the furan ring in dogs (Kolis et al., 1979), and furan-containing chemicals are metabolized by opening of the fused ring (Sahali-Sahly et al., 1996). In other words, furanocoumarin metabolism leads to CYP 1A2 isozyme destruction and a reduction of caffeine-metabolizing activity in humans. This has been termed "suicide enzyme inhibition" (Letteron et al., 1986; Clewell and Andersen, 1987; Mays et al., 1990). Once the CYP 1A2 isozyme is deactivated, its activity can only be regained by isozyme re-synthesis. The time required to

\section{REFERENCES}

Akter, S., Kashino, I., Mizoue, T., Matsuo, K., Ito, H., Wakai, K., et al. (2016). Coffee drinking and colorectal cancer risk: an evaluation based on a systematic review and meta-analysis among the Japanese population. Jpn. J. Clin. Oncol. 46 (8), 781-787. doi:10.1093/jjco/hyw059

Alehaideb, Z., Chin, K. C., Yao, M. C., and Law, F. C. P. (2019). Predicting the content of anthraquinone bioactive in Rhei rhizome (Rheum officinale Baill.) with the concentration addition model. Saudi Pharm. J. 27 (1), 25-32. doi:10. 1016/j.jsps.2018.07.015 regenerate CYP $1 \mathrm{~A} 2$ activity after its destruction is long and this explains why the ARFP products still are able to inhibit caffeine metabolism in humans treated with a single oral dose of ARFP extract $3.0 \mathrm{~h}$ before.

\section{CONCLUSION}

Pre- or co-administration of caffeine and ARFP products may result in CYP 1A2 inactivation, caffeine overdose, and serious health consequences. As such, care must be exercised when furanocoumarin-rich plant products are co-administered with drugs that are substrates of the CYP 1A2 isozyme. Our studies also support the development of regulations for proper labeling of natural health products and functional foods that contain inhibitors of CYP enzymes.

\section{DATA AVAILABILITY STATEMENT}

The original contributions presented in the study are included in the article/Supplementary Material, further inquiries can be directed to the corresponding author.

\section{ETHICS STATEMENT}

The studies involving human participants were reviewed and approved by Simon Fraser University Ethics Office. The patients/ participants provided their written informed consent to participate in this study.

\section{AUTHOR CONTRIBUTIONS}

All authors listed have made a substantial, direct, and intellectual contribution to the work and approved it for publication.

\section{ACKNOWLEDGMENTS}

We thank King Abdullah International Medical Research Center and Saudi Ministry of National Guard-Health Affairs in providing a scholarship for ZA.

Alehaideb, Z., Sheriffdeen, M., and Law, F. C. P. (2017). Furanocoumarin bioactives in the Apiaceae and Rutaceae families of plants. Canad. J. Pure Appl. Sci. 11, 4157-4167.

Atsdr, U. (2004). Guidance manual for the assessment of joint toxic action of chemical mixtures. Atlanta: US Department of Health and Human ServicesPublic Health Service, Agency for Toxic Substances and Disease Registry.

Berenbaum, M. (1983). Coumarins and caterpillars: a case for coevolution. Evolution, 163-179. doi:10.2307/2408184

Blanchard, J., and Sawers, S. J. A. (1983). The absolute bioavailability of caffeine in man. Eur. J. Clin. Pharmacol. 24 (1), 93-98. doi:10.1007/bf00613933 
Bloomer, J. C., Clarke, S. E., and Chenery, R. J. (1995). Determination of P4501A2 activity in human liver microsomes using [3-14C-methyl]caffeine. Xenobiotica 25 (9), 917-927. doi:10.3109/00498259509046663

Cai, Y., Bennett, D., Nair, R. V., Ceska, O., Ashwood-Smith, M. J., and DiGiovanni, J. (1993). Inhibition and inactivation of murine hepatic ethoxy- and pentoxyresorufin O-dealkylase by naturally occurring coumarins. Chem. Res. Toxicol. 6 (6), 872-879. doi:10.1021/tx00036a018

Cao, Y., Zhong, Y. H., Yuan, M., Li, H., and Zhao, C. J. (2013). [Inhibitory effect of imperatorin and isoimperatorin on activity of cytochrome P450 enzyme in human and rat liver microsomes]. Zhongguo Zhong Yao Za Zhi 38 (8), 1237-1241. doi:10.4268/cjcmm20130823

Clewell, H. J., III, and Andersen, M. E. (1987). Dose, species, and route extrapolation using physiologically based pharmacokinetic models. Drinking Water and Health, Volume 8: Pharmacokinetics in risk assessment, 111-131.

FAOSTAT (2009). Food and Agriculture Organization Statistical database. Global sales of coffee, tea, and cocoa. Retrieved from http://www.fao.org.

Fouin-Fortunet, H., Tinel, M., Descatoire, V., Letteron, P., Larrey, D., Geneve, J., et al. (1986). Inactivation of cytochrome P-450 by the drug methoxsalen. J. Pharmacol. Exp. Ther. 236, 237-247.

Fuhr, U., Klittich, K., and Staib, A. (1993). Inhibitory effect of grapefruit juice and its bitter principal, naringenin, on CYP1A2 dependent metabolism of caffeine in man. Br. J. Clin. Pharmacol. 35 (4), 431-436. doi:10.1111/j.1365-2125.1993.tb04162.x

Glade, M. J. (2010). Caffeine-Not just a stimulant. Nutrition 26 (10), 932-938. doi:10.1016/j.nut.2010.08.004

Goldstein, E. R., Ziegenfuss, T., Kalman, D., Kreider, R., Campbell, B., Wilborn, C., and Wildman, R. (2010). International society of sports nutrition position stand: caffeine and performance. J. Int. Soc. Sports Nutr. 7 (1), 1-15. doi:10. 1186/1550-2783-7-5

Guo, L. Q., and Yamazoe, Y. (2004). Inhibition of cytochrome P450 by furanocoumarins in grapefruit juice and herbal medicines. Acta Pharmacol. Sin 25 (2), 129.

Jabbar, S. B., and Hanly, M. G. (2013). Fatal caffeine overdose. Am. J. forensic Med. Pathol. 34 (4), 321-324. doi:10.1097/paf.0000000000000058

Jollow, D. J., Mitchell, J. R., Porter, W. Z., Davis, D. C., Gillette, J. R., and Brodie, B. B. (1973). Acetaminophen-induced hepatic necrosis. II. Role of covalent binding in vivo. J. Pharmacol. Exp. Ther. 187, 195-202.

Kamimori, G. H., Lugo, S. I., Penetar, D. M., Chamberlain, A. C., Brunhart, G. E., Brunhart, A. E., et al. (1995). Dose-dependent caffeine pharmacokinetics during severe sleep deprivation in humans. Int. J. Clin. Pharmacol. Ther. 33 (3), 182-186.

Kang, A.-Y., Young, L. R., Dingfelder, C., and Peterson, S. (2011). Effects of furanocoumarins from apiaceous vegetables on the catalytic activity of recombinant human cytochrome P-450 1A2. Protein J. 30 (7), 447-456. doi:10.1007/s10930-011-9350-0

Ko, F.-N., Wu, T.-S., Liou, M.-J., Huang, T.-F., and Teng, C.-M. (1989). Inhibition of platelet thromboxane formation and phosphoinositides breakdown by osthole from Angelica pubescens. Thromb. Haemost. 62 (03), 996-999. doi:10.1055/s-0038-1651041

Koenigs, L. L., Peter, R. M., Thompson, S. J., Rettie, A. E., and Trager, W. F. (1997). Mechanism-based inactivation of human liver cytochrome P450 2A6 by 8methoxypsoralen. Drug Metab. Dispos 25 (12), 1407-1415.

Kolis, S. J., Williams, T. H., Postma, E. J., Sasso, G. J., Confalone, P. N., and Schwartz, M. A. (1979). The metabolism of 14C-methoxsalen by the dog. Drug Metab. Dispos 7 (4), 220-225.

Kot, M., and Daniel, W. A. (2008). Caffeine as a marker substrate for testing cytochrome P450 activity in human and rat. Pharmacol. Rep. 60 (6), 789-797. doi:10.1016/j.bcp.2008.05.025

Law, F. C. P., and Chakrabarti, S. (1983). Irreversible binding of14C-diphenyl ether-derived radioactivity to liver microsomesin vitroand tissoe proteinsin vivo. Drug Chem. Toxicol. 6 (3), 285-294. doi:10.3109/01480548309017819

Law, F. C. P., and Meng, J. (1996). Binding of14C-furazolidone metabolites to the muscular and hepatic proteins of trout*. Food Additives and Contaminants 13 (2), 199-209. doi:10.1080/02652039609374398

Law, F. C., Yao, M., Bi, H. C., and Lam, S. (2017). Physiologically based pharmacokinetic modeling of tea catechin mixture in rats and humans. Pharmacol. Res. Perspect. 5 (3), e00305. doi:10.1002/prp2.305

Letteron, P., Descatoire, V., Larrey, D., Tinel, M., Geneve, J., and Pessayre, D. (1986). Inactivation and induction of cytochrome P-450 by various psoralen derivatives in rats. J. Pharmacol. Exp. Ther. 238, 685-692.
Li, J., Ma, B., Zhang, Q., Yang, X., Sun, J., Tang, B., et al. (2014). Simultaneous determination of osthole, bergapten and isopimpinellin in rat plasma and tissues by liquid chromatography-tandem mass spectrometry. J. Chromatogr. $B$ 970, 77-85. doi:10.1016/j.jchromb.2014.06.014

Lim, H.-K., Duczak, N., Brougham, L., Elliot, M., Patel, K., and Chan, K. (2005). Automated screening with confirmation of mechanism-based inactivation of Cyp3a4, Cyp2C9, Сyp2C19, Cyp2D6, and Cyp1a2 in pooled human liver microsomes. Drug Metab. Dispos. 33, 1211-1219. doi:10.1124/dmd.104.003475

Lipton, R. B., Hans-Christoph, D., Matthew, S. R., Yacoub, S. G., and Patel, K. (2017). Caffeine in the management of patients with headache. J. Headache Pain 18, 107. doi:10.1186/s10194-017-0806-2

Liu, Z., Jiang, M., Lu, X., Qin, F., Song, Y., Wen, J., et al. (2012). Simultaneous determination of pimpinellin, isopimpinellin and phellopterin in rat plasma by a validated UPLC-MS/MS and its application to a pharmacokinetic study after administration of Toddalia asiatica extract. J. Chromatogr. B 891-892, 102-108. doi:10.1016/j.jchromb.2012.02.022

Mays, D. C., Hilliard, J. B., Wong, D. D., Chambers, M. A., Park, S. S., Gelboin, H. V., et al. (1990). Bioactivation of 8-methoxypsoralen and irreversible inactivation of cytochrome P-450 in mouse liver microsomes: modification by monoclonal antibodies, inhibition of drug metabolism and distribution of covalent adducts. J. Pharmacol. Exp. Ther. 254, 720-731.

Mays, D. C., Camisa, C., Cheney, P., Pacula, C. M., Nawoot, S., and Gerber, N. (1987). Methoxsalen is a potent inhibitor of the metabolism of caffeine in humans. Clin. Pharmacol. Ther. 42 (6), 621-626. doi:10.1038/clpt.1987.209

Meyer, H., Bolarinwa, A., Wolfram, G., and Linseisen, J. (2006). Bioavailability of apigenin from apiin-rich parsley in humans. Ann. Nutr. Metab. 50, 167-172. doi:10.1159/000090736

Nawrot, P., Jordan, S., Eastwood, J., Rotstein, J., Hugenholtz, A., and Feeley, M. (2003). Effects of caffeine on human health. Food Additives and Contaminants 20, 1-30. doi:10.1080/0265203021000007840

Perera, V., Gross, A. S., and McLachlan, A. J. (2010). Caffeine and paraxanthine HPLC assay for CYP1A2 phenotype assessment using saliva and plasma. Biomed. Chromatogr. 24, 1136-1144. doi:10.1002/bmc.1419

Peterson, S., Lampe, J. W., Bammler, T. K., Gross-Steinmeyer, K., and Eaton, D. L. (2006). Apiaceous vegetable constituents inhibit human cytochrome P-450 1A2 (hCYP1A2) activity and hCYP1A2-mediated mutagenicity of aflatoxin B1. Food Chem. Toxicol. 44, 1474-1484. doi:10.1016/j.fct.2006.04.010

Sahali-Sahly, Y., Balani, S. K., Lin, J. H., and Baillie, T. A. (1996). In VitroStudies on the metabolic activation of the furanopyridine L-754,394, a highly potent and selective mechanism-based inhibitor of cytochrome P450 3A4. Chem. Res. Toxicol. 9, 1007-1012. doi:10.1021/tx960060b

Shephard, S. E., Zogg, M., Burg, G. x. n., and Panizzon, R. G. (1999). Measurement of 5-methoxypsoralen and 8-methoxypsoralen in saliva of PUVA patients as a noninvasive, clinically relevant alternative to monitoring in blood. Arch. Dermatol. Res. 291, 491-499. doi:10.1007/s004030050443

Sheriffdeen, M. M., Alehaideb, Z. I., and Law, F. C. P. (2019). Caffeine/Angelica dahurica and caffeine/Salvia miltiorrhiza metabolic inhibition in humans: in vitro and in vivo studies. Complement. Therapies Med. 46, 87-94. doi:10. 1016/j.ctim.2019.07.024

Shimada, T., Yamazaki, H., Mimura, M., Inui, Y., and Guengerich, F. P. (1994). r. J. Pharmacol. Exp. Ther. 270, 414-423.

Siddiqui, A. H., Stolk, L. M. L., and Cormane, R. H. (1984). Comparison of serum levels and clinical results of PUVA therapy with three different dosage forms of 8-methoxypsoralen. Arch. Dermatol. Res. 276, 343-345. doi:10.1007/ bf00404632

Stolk, L. M. L., Westerhof, W., Cormane, R. H., and Zwieten, P. A. V. (1981). Serum and urine concentrations of 5-methoxypsoralen after oral administration. Br. J. Dermatol. 105, 415-420. doi:10.1111/j.1365-2133.1981.tb00772.x

Tang-Liu, D. D., Williams, R. L., and Riegelman, S. (1983). Disposition of caffeine and its metabolites in man. J. Pharmacol. Exp. Ther. 224, 180-185.

Tian, D.-D., Natesan, S., White, J. R., Jr., and Paine, M. F. (2019). Effects of common CYP1A2 genotypes and other key factors on intraindividual variation in the caffeine metabolic ratio: an exploratory analysis. Clin. Transl. Sci. 12, 39-46. doi:10.1111/cts.12598

Tinel, M., Belghiti, J., Descatoire, V., Amouyal, G., Letteron, P., Geneve, J., et al. (1987). Inactivation of human liver cytochrome P-450 by the drug methoxsalen and other psoralen derivatives. Biochem. Pharmacol. 36, 951-955. doi:10.1016/ 0006-2952(87)90190-0 
Villeneuve, D. L., Blankenship, A. L., and Giesy, J. P. (2000). Derivation and application of relative potency estimates based on in vitro bioassay results. Environ. Toxicol. Chem. 19, 2835-2843. doi:10.1002/etc.5620191131

Walther, T., Quednow, B., Haustein, U. F., and Meyer, F. P. (1992). Variability of serum levels for three oral 8-methoxypsoralen brands. Photodermatol. Photoimmunol Photomed. 9, 1-3.

Wikoff, D., Welsh, B. T., Henderson, R., Brorby, G. P., Britt, J., Myers, E., et al. (2017). Systematic review of the potential adverse effects of caffeine consumption in healthy adults, pregnant women, adolescents, and children. Food Chem. Toxicol. 109, 585-648. doi:10.1016/j.fct.2017.04.002

Yang, L.-P., Zhou, Z.-W., Chen, X.-W., Li, C. G., Sneed, K. B., Liang, J., et al. (2012). Computational andin vitrostudies on the inhibitory effects of herbal compounds on human cytochrome P450 1A2. Xenobiotica 42, 238-255. doi:10.3109/00498254.2011.610833

Zhang, Y., Huo, M., Zhou, J., and Xie, S. (2010). PKSolver: an add-in program for pharmacokinetic and pharmacodynamic data analysis in Microsoft Excel. Comp. Methods Programs Biomed. 99, 306-314. doi:10.1016/j.cmpb.2010.01.007
Zhuang, X.-M., Zhong, Y.-H., Xiao, W.-B., Li, H., and Lu, C. (2013). Identification and characterization of psoralen and isopsoralen as potent CYP1A2 reversible and time-dependent inhibitors in human and rat preclinical studies. Drug Metab. Dispos. 41, 1914-1922. doi:10.1124/dmd. 113.053199

Conflict of Interest: The authors declare that the research was conducted in the absence of any commercial or financial relationships that could be construed as a potential conflict of interest.

Copyright (c) 2021 Alehaideb, Sheriffdeen and Law. This is an open-access article distributed under the terms of the Creative Commons Attribution License (CC BY). The use, distribution or reproduction in other forums is permitted, provided the original author(s) and the copyright owner(s) are credited and that the original publication in this journal is cited, in accordance with accepted academic practice. No use, distribution or reproduction is permitted which does not comply with these terms. 